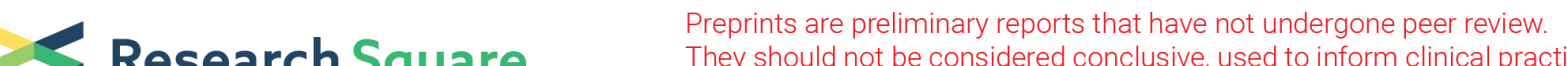 Research Square They should not be considered conclusive, used to inform clinical practice, or referenced by the media as validated information.
}

\section{Nurse-performed ultrasonography in combat operations: a perspective for the future?}

\section{Kevin Balasoupramanien ( $\nabla$ kevinbala@hotmail.fr)}

Hôpital d'instruction des armées Laveran https://orcid.org/0000-0003-2830-4092

\section{Guillaume Comat}

Antenne médicale de Calvi, Centre Médical des Armées de Marseille

\section{Aurélien Renard}

Service d'accueil des urgences, Hopital d'Instruction des Armées Saint-Anne,Toulon

Jean-Guillaume Meusnier

Antenne médicale de Varces, Centre médical des armées de Lyon

\section{Coline Montigon}

Antenne médicale de Phalsbourg, Centre Médical des Armées de Phalsbourg

\section{Anne-Sophie Pitel}

Antenne médicale de Sarrebourg, Centre Médical des Armées de Strasbourg

\section{Marc Bascou}

Antenne médicale de Nansouty, Centre Médical des Armées de Bordeaux

\section{Rémy Dubourg}

Etat-major opérationnel Santé

\section{Nicolas Cazes}

Service médical d'urgence, Bataillon de marins-pompiers de Marseille

\section{Research}

Keywords: ultrasonography, military medicine, military nurse

Posted Date: April 16th, 2021

DOI: https://doi.org/10.21203/rs.3.rs-426681/v1

License: (c) (1) This work is licensed under a Creative Commons Attribution 4.0 International License.

Read Full License 


\section{Abstract}

Background In current French military operations, it is not uncommon for the military nurses (MNs) to be required to support soldiers alone in isolated areas. At a time when advanced practice nurses in the civilian sector develop extended skills, we asked MNs about their willingness to be trained in point-of-care ultrasound (POCUS).

Methods We conducted a web-based survey from 1 November 2018 to 1 December 2018, including all MNs deployed in the Barkhane operation. The questionnaire, sent by e-mail, aimed to describe the willingness of MNs to be trained in POCUS. Their opinion on the usefulness of this training, the situations and ultrasound targets that seemed most profitable to them were also studied.

Results 30 questionnaires out of 34 were completed. On average, MNs had 7.4 years of practice and had already carried out three military operations. Three MNs reported having been trained in POCUS and six had already performed POCUS on the field. $96 \%$ of the untrained MNs wanted to be trained. Twenty-nine (96\%) MNs felt that there was added value in knowing how to perform POCUS, especially in operations and in isolated posts without a military physician (MP). Focused assessment with sonography for trauma, pleural and urinary tract ultrasound were the targets considered most useful to them, in that order.

Conclusion MNs are interested in learning POCUS. A training course before their departure on mission for simple and quick acquisition targets would be easy to implement and probably beneficial for the patient, the MN and the MP.

\section{Background}

In military operations, the French defence health service is committed to provide emergency and routine health care as close to the operations as possible.

According to the anticipated combat operation duration, intensity and time-to-medical evacuation, medical support is normally provided by a military nurse-physician pair or by a military physician alone. In the Barkhane operation (Additional file 1), the fight against terrorist armed groups in the SaheloSaharan band consists mostly in deploying small fighting units in remote areas, often with combat medics and a military nurse (MN) as the only medical support.

In the absence of a military physician (MP), an advanced level three training course in tactical combat casualty care, common for the MN and MP, allows the nurse to stabilise a wounded soldier alone while waiting for the medical evacuation team. The course assures the acquisition of a high level of knowledge in traumatology and the practice of specialised medical procedures.

For MPs, additional in-depth training course in tactical ultrasound (US) are offered, given its utility in resource-scarce situations to help the diagnostic, treatment and evacuation decisions. Ultrasonography 
has now become a mandatory component of every military medical residency training. The recent preliminary results of extended focused assessment with sonography for trauma (E-FAST) performed by medical trainees in combat-like exercise conditions shows its feasibility and its usefulness to guide therapeutic decisions and medical evacuation priorities (1).

Even though MNs and MPs follow the same tactical combat casualty care course, complementary training on tactical US is not accessible to MNs deployed in foreign operations.

At a time where ultrasonography becomes the extension of clinical examination and a validated aid to medical decision in the battlefield, we questioned our MNs on their willingness to be trained in clinical ultrasonography.

\section{Materials And Methods}

We conducted a descriptive multicentre study through a survey addressed to all French MNs deployed in the Barkhane operation (East and West Zones) from 1 November 2018 to 1 December 2018. The survey was first validated by the medical director of Barkhane operation located at the joint theatre command post in N'Djamena, Chad (Additional file 2).

It was then distributed electronically via the operational intranet. Each MP responsible for a forward medical post (Role 1), surgical antenna (Role 2), aeromedical evacuation team and vital surgery unit received the questionnaire and forwarded it to the MNs under his command.

Responses were collected either electronically by return e-mail or in paper form after printing the questionnaire. After 15 days, a reminder e-mail was sent to the medical facilities that had not responded.

After a short explanation of the study objective, the first part of the questionnaire collected demographic data aiming to describe the $\mathrm{MN}$ : nursing career, years of practice, number of missions and type of position held during the current mission.

The second part of the survey was designed to find out:

- Their previous clinical US training and their willingness to be trained.

- Their previous clinical US practice.

- Their opinion on the added value of a MN trained in US.

- The US targets they considered most useful to acquire.

- The presence of an US scanner in their nurse-physician pair.

The questionnaires were all anonymised by a third party who collected them. This observational study was waived from ethics board approval.

\section{Results}


Of 34 MNs surveyed, 30 completed the questionnaires. On average, they had 7.4 years of practice and had already carried out three overseas missions. Seventy-three per cent had a curriculum exclusively in military units, $10 \%$ only in military teaching hospitals and $17 \%$ in both (Table 1 ).

Table 1

Demographic data of the MNs surveyed

\begin{tabular}{|l|l|}
\hline Demographic data & $\mathbf{N}(\%)$ \\
\hline Years of practice (average) & 7.4 \\
\hline Curriculum in military units only & $25(74.5 \%)$ \\
\hline Curriculum in military teaching hospitals only & $4(12 \%)$ \\
\hline Curriculum in both (hospitals and military units) & $5(14.5 \%)$ \\
\hline Number of missions accomplished as a nurse (average) & 3 \\
\hline Type of position held during the mandate & \\
\hline Role 1 & $19(55 \%)$ \\
\hline Role 2 & $5(15 \%)$ \\
\hline HM medevac & $3(9 \%)$ \\
\hline Casanurse & $3(9 \%)$ \\
\hline Special unit/Commando unit & $4(12 \%)$ \\
\hline
\end{tabular}

Three MNs reported having training in clinical ultrasonography and $96 \%$ of the untrained were willing to join a specific course.

Six reported having already performed US examination in real-life situations. Focused assessment with sonography for trauma (FAST) was the most common examination performed, followed by biliary and lower extremity deep vein examination.

Twenty-nine (96\%) of the MNs surveyed felt that there was an added value in knowing how to perform a clinical ultrasonography, especially in isolated posts without a physician (94\%), in overseas missions (82\%) rather than in military units in metropolitan France (17\%) and in the physician-nurse pair (50\%) (Fig. 1: Added value situations for MN-performed POCUS).

In order of importance, targets considered most useful to them were the FAST (100\%), pleural (79\%) and urinary tract examination (67\%), followed by the venous access guidance $(38 \%)$, resuscitation evaluation (20\%) and lower extremity deep vein examination (20\%) (Fig. 2: Useful US targets according to the MNs surveyed). 
Ninety per cent of physician-nurse pairs were already equipped with US scanners in the Barkhane operation.

\section{Discussion}

The aim of the military health system on the battlefield is to preserve the fighting force in an austere, resource-scarce environment in order to accomplish the military objective. In those conditions, medical care of injured and ill soldiers is a challenging task. Moreover, their evacuation to higher level of care requires manpower, use of limited resource and risk of injury or death to those involved in transporting the patient. Thus, any information that can be gleaned as close to the initial point of injury is critical in accomplishing the mission, conserving resources and preserving the fighting force.

A portable US scanner that fits in a backpack is a precious imaging modality which provides critical information, guiding diagnostic and therapeutic decisions as well as medical evacuation priorities.

The majority of MNs surveyed recognise the usefulness of US in isolated posts and would like to be trained to improve the management of their patients in deteriorated situations. Twenty per cent have already performed US examinations after learning it from the MPs they work with in metropolitan France and in foreign operations. They do not wish to become sonographers, but rather carry out certain targeted examinations after dedicated training and act within the framework of protocols. Given the accessibility of US scanners in foreign operations, training our MNs is a serious path we need to explore.

The FAST examination is recognised as the most useful target the nurses surveyed wanted to acquire. The basic examination includes the upper right and left abdomen, cardiac and pelvic views. This first line imaging assesses for intra-thoracic and intra-abdominal traumatic injury, providing information for guiding triage, treatment and evacuation priorities.

In a civilian setting, Bowra et al. (2) assessed the accuracy of nurse-performed FAST examination for the detection of free fluid in the peritoneal cavity and pericardial space in patients brought to the emergency department following trauma after a 1-day training course and a minimum of 25 supervised validated scans. The results are encouraging, with an overall accuracy of $95 \%$, similar to physician performance. In a military setting, Monti et al. (3) showed that a 4-hour introductory e-FAST training intervention among ultrasound-naïve U.S. military medics allows them to perform as well as previously trained emergency medicine physicians.

The pleural US examination considered as secondary target by the MNs presents a real added value in the noisy environment of a battlefield where physical examination is limited and X-ray often unavailable, in order to provide an early diagnosis of a tension pneumothorax and/or hemothorax. In various civilian and military studies, the ability of non-physicians to perform and interpret pleural US examination shows high level of sensitivity and specificity (4-6). 
Renal US examination, venous access guidance, resuscitation evaluation and lower extremity deep vein examination are of interest in the diagnosis of pathologies caused by the operational constraints (dehydration and kidney stones linked to the hot desert climate, hypovolemia and intravascular volume evaluation to guide fluid resuscitation in trauma related or medical pathologies, prolonged sitting in the convoys and thrombosis). As for the FAST and pleural examination, evidence from the available studies point out the ability and accuracy of non-physicians to perform specific US examinations (7-10).

Morgan et al. (11) showed that US examinations can be implemented in a deployment environment. Twenty-nine special forces medical sergeants performed 109 US examinations in a 1-year deployment period after an average of 16.7 hours didactic training and 8 to 52 hours of practical training over 2 years. That encouraging experience led the U.S. military physicians to develop a 24 hours curriculum of didactic and hands-on US training for special operations medics: The Special Operator Level Clinical Ultrasound (SOLCUS).

Similarly, we can expect our MNs to perform reliable US examinations after a brief training course. Several curricula should be assessed to introduce this skill.

Brief US theoretical training and practical examinations under the supervision of experienced physicians could be included in military nursing studies. Cazes et al. (12) assessed the number of US examinations required to perform reliable diagnosis on 10 novice military generalist practitioners without previous experience during their residency. After 2 hours of theoretical training, a minimum of 30 FAST and 20 pleural examinations were sufficient to assure optimal performance.

We also need to consider adapting and opening the complementary course on tactical US for MNs during their level three tactical combat casualty care training to ensure acquisition of quick and practical US targets. It could be a step towards the training of an upskilled workforce qualified in advanced practice, even though this new concept requires further work to define their operational role within military prehospital care (13).

\section{Conclusion}

Ultrasonography is a real asset for the medical team in foreign operations. Considering the increasing situations where the $\mathrm{MN}$ is isolated and represents the only medical support to the fighting units, the defence health service has to provide them with all the necessary tools for providing optimal medical care in degraded conditions. The vast majority of MNs are interested in learning clinical US. Scientific data available tends to prove their ability to perform reliable targeted US examinations on the field after a brief training course.

\section{List Of Abbreviations}

MN: Military Nurse 
MP: Military Physician

US: Ultrasound

POCUS: Point-Of-Care Ultrasound

E-FAST: Extended Focused Assessment with Sonography for Trauma

\section{Declarations}

\section{Ethics approval}

This observational study waived from ethics board approval.

\section{Consent for publication}

Not applicable

\section{Availability of data and materials}

The datasets used and/or analysed during the current study are available from the corresponding author on reasonable request.

\section{Competing interests}

The authors declare that they have no competing interests.

\section{Funding}

The authors have not declared a specific grant for this research from any funding agency in the public, commercial or not-for-profit sectors.

\section{Author's contributions}

KB: formal analysis; data curation; writing: original draft, review and editing

GC: conceptualization; investigation; software; writing: review and editing

AR: conceptualization; methodology; formal analysis; supervision

JGM: investigation;

CM: investigation;

ASP: investigation;

$M B$ : investigation; 
RD: methodology; project administration; supervision

NC: conceptualization; methodology; investigation; software; writing: review and editing

\section{Acknowledgments}

Not applicable.

\section{Disclaimer}

The views expressed are solely those of the authors and do not reflect the official policy or position of the French Armed Forces.

\section{References}

1. Renard A, Martinet C, Cungi PJ, Combes E, Gasperini G, Cazes N, et al. Is E-FAST possible and useful on the battlefield? A feasibility study during medical courses in hostile environment (MEDICHOS): preliminary results. J R Army Med Corps oct. 2019;165(5):338-41.

2. Bowra J, Forrest-Horder S, Caldwell E, Cox M, D’Amours SK. Validation of nurse-performed FAST ultrasound. Injury mai. 2010;41(5):484-7.

3. Monti JD, Perreault MD. Impact of a 4-hour Introductory eFAST Training Intervention Among Ultrasound-Naïve U.S. Military Medics. Mil Med 8 juin. 2020;185(5-6):e601-8.

4. Swamy V, Brainin P, Biering-Sørensen T, Platz E. Ability of non-physicians to perform and interpret lung ultrasound: A systematic review. Eur J Cardiovasc Nurs août. 2019;18(6):474-83.

5. Mumoli N, Vitale J, Giorgi-Pierfranceschi M, Cresci A, Cei M, Basile V, et al. Accuracy of NursePerformed Lung Ultrasound in Patients With Acute Dyspnea: A Prospective Observational Study. Medicine (Baltimore). mars 2016;95(9):e2925.

6. Meadows RM, Monti JD, Umar MA, Van Arnem KA, Chin EJ, Mitchell CA, et al. US Army Combat Medic Performance With Portable Ultrasound to Detect Sonographic Findings of Pneumothorax in a Cadaveric Model. J Spec Oper Med. 2020;20(3):71-5.

7. Kuo C-C, Wu C-Y, Feng I-J, Lee W-J. [Efficacy of Ultrasound-Guided Peripheral Intravenous Access: A Systematic Review and Meta-Analysis]. Hu Li Za Zhi déc. 2016;63(6):89-101.

8. Hutchings S, Bisset L, Cantillon L, Keating-Brown P, Jeffreys S, Muzvidziwa C, Richmond E, Rees P. Nurse-delivered focused echocardiography to determine intravascular volume status in a deployed maritime critical care unit. J R Nav Med Serv. 2015;101(2):124-8.

9. Páez A, Juárez N, Marín M, Del Vigo S, Redondo E, Durán M. Concordance analysis of ultrasonographic diagnoses by urology nurses. Arch Esp Urol déc. 2012;65(10):872-8.

10. Mumoli N, Vitale J, Cocciolo M, Cei M, Brondi B, Basile V, et al. Accuracy of nurse-performed compression ultrasonography in the diagnosis of proximal symptomatic deep vein thrombosis: a prospective cohort study. J Thromb Haemost avr. 2014;12(4):430-5. 
11. Morgan AR, Vasios WN, Hubler DA, Benson PJ. Special operator level clinical ultrasound: an experience in application and training. J Spec Oper Med. 2010 Spring;10(2):16-21.

12. Cazes N, Desmots F, Geffroy Y, Renard A, Leyral J, Chaumoître K. Emergency ultrasound: A prospective study on sufficient adequate training for military doctors. Diagn Interv Imaging 1 nov. 2013;94(11):1109-15.

13. Paxman E, Lamb D, Findlay S. BMJ Mil Health Epub ahead of print: [9 Apr 2021]. doi:10.1136/bmjmilitary-2021-001781.

\section{Figures}

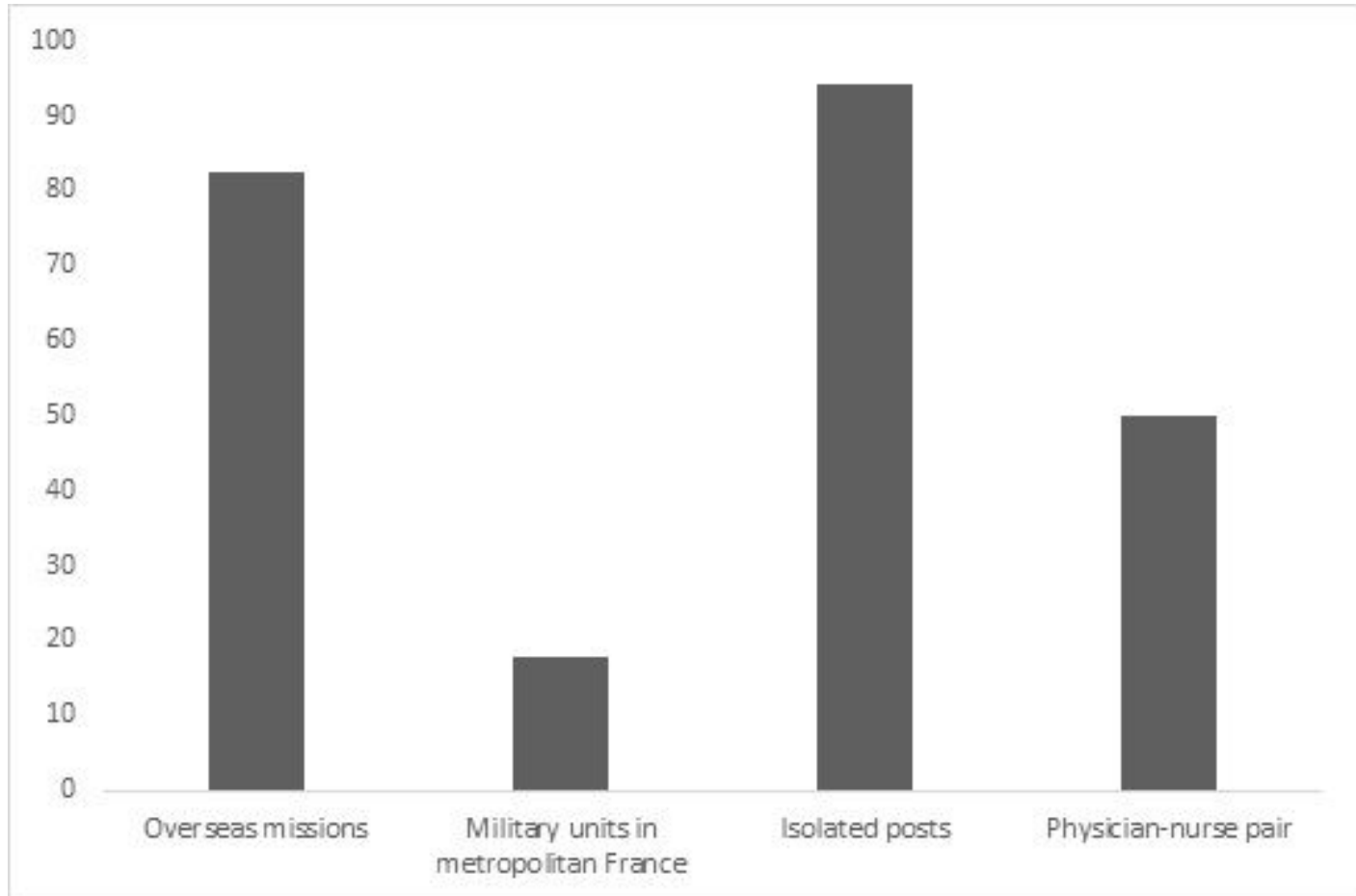

\section{Figure 1}

Added value situations for MN-performed POCUS. 


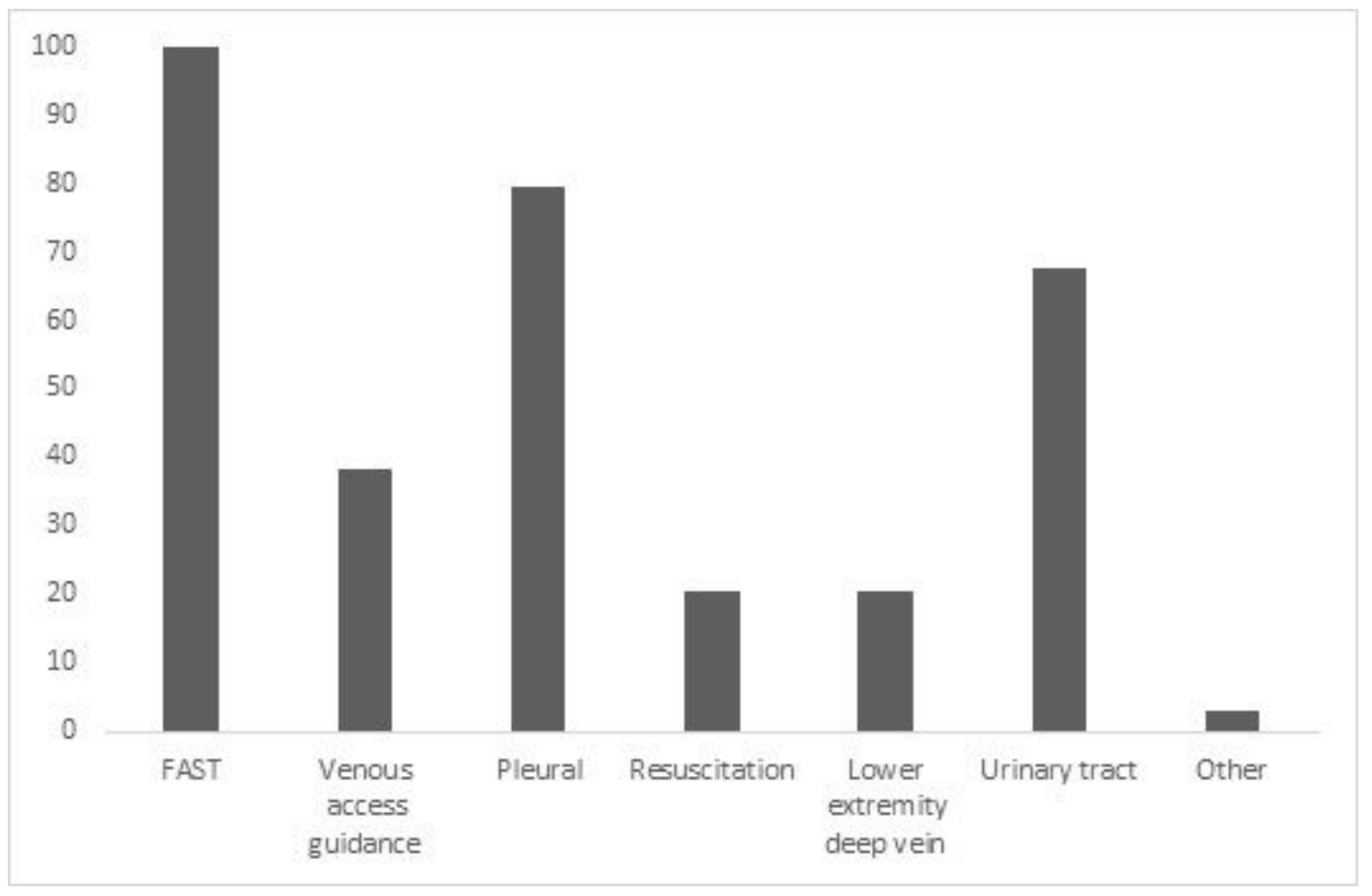

Figure 2

Useful US targets according to the MNs surveyed.

\section{Supplementary Files}

This is a list of supplementary files associated with this preprint. Click to download.

- Additionalfile10perationBarkhane.docx

- Additionalfile2Questionnaires.docx 